\title{
Interaction of Atmospheric Gases with ETS-10: A DFT study
}

\author{
Renjith S. Pillai, ${ }^{1}$ Miguel Jorge, ${ }^{2}$ José R. B. Gomes ${ }^{1, *}$
}

${ }^{1}$ CICECO, Departamento de Química, Universidade de Aveiro, Campus Universitário de Santiago, P-3810-193 Aveiro, Portugal

${ }^{2}$ Department of Chemical and Process Engineering, University of Strathclyde, 75 Montrose Street, Glasgow G1 1XJ, United Kingdom

*Corresponding author. E-mail: jrgomes@ua.pt

Phone: +351234401423

Fax: +351234401470 


\begin{abstract}
Density functional theory (DFT) was used to optimize the geometries and calculate the enthalpies for the interactions between polar $\left(\mathrm{H}_{2} \mathrm{O}\right)$, quadrupolar $\left(\mathrm{CO}_{2}\right.$ and $\left.\mathrm{N}_{2}\right)$, and apolar $\left(\mathrm{H}_{2}\right.$ and $\mathrm{CH}_{4}$ ) atmospheric gases with a cluster model of the Engelhard titanosilicate ETS-10 having sodium extra framework cations (Na-ETS-10). The DFT calculations were performed with different exchange-correlation functionals and were corrected for the basis set superposition error with the counterpoise method. The calculated enthalpies for the interaction of the five gases with Na-ETS-10 decrease in the order $\mathrm{H}_{2} \mathrm{O}>\mathrm{CO}_{2}>>\mathrm{N}_{2} \approx \mathrm{CH}_{4}>\mathrm{H}_{2}$ and compare well with experimental data available in the literature. The enthalpies calculated at the M06-L/6$31++\mathrm{G}(\mathrm{d}, \mathrm{p})$ level of theory for the two extreme cases, i.e., strongest and weakest interactions, are $-60.6 \mathrm{~kJ} / \mathrm{mol}\left(\mathrm{H}_{2} \mathrm{O}\right)$ and $-12.2 \mathrm{~kJ} / \mathrm{mol}\left(\mathrm{H}_{2}\right)$. Additionally, the calculated vibrational frequencies are in very good agreement, within the approximations of the method, with the characteristic vibrational modes of ETS-10 and of the interactions of gases with $\mathrm{Na}^{+}$in the 12 -membered channel in ETS-10.
\end{abstract}

Keywords: ETS-10; Sorption; Separation; Atmospheric gases; DFT calculations 


\section{Introduction}

Titanosilicates form a class of molecular sieves with interesting porous structures for many applications, ranging from catalysis to adsorption and ion-exchange [1-3]. An interesting material belonging to the family of titanosilicates is the Engelhard titanosilicate ETS-10, which is a microporous zeotype material containing titanate chains originating lines of corner-sharing $\mathrm{TiO}_{6}$ octahedra embedded in a silica framework. In this material, each $\mathrm{TiO}_{6}$ in the framework has an associated charge of -2 that is compensated by extra-framework exchangeable cations $[2,4$, 5]. The charge-balancing species exist in the structure and can be replaced by other ions. These titanosilicates show good catalytic and separation properties: They have been applied as potential heterogeneous catalysts [6-9], photo catalysts $[10,11]$ and have been utilized also in the stabilization of radical cations. ETS-10 materials have the capability of acting as ion exchangers for heavy metals $[12,13]$ and, therefore, found application as selective heavy metal removal materials $[14,15]$. When ETS-10 materials are used in catalysis, their catalytic activity can be tuned by careful selection of the charge-balancing ions.

Similarly, adsorption capacities and selectivity of gases on ETS-10 can be modified also by ion-exchange, and these characteristics can be exploited, for instance, to design appropriate adsorbents for temperature/pressure swing adsorption (TSA/PSA) techniques [16-22]. Indeed, several authors $[17,18,20,23,24]$ suggested ETS-10 as an adsorbent for gas separation processes. Al-Baghli et al. [17] and Anson et al. [20] reported that $\mathrm{CH}_{4}$ and hydrocarbons can be captured utilizing the PSA technique, while Kuznicki et al [1, 22, 25] evidenced the good capacities of ETS-10 to separate $\mathrm{N}_{2}$ from landfill gas [22] and air [25]. Moreover, Park et al [21] found that $\mathrm{CO}_{2}$ can be separated from its mixture with $\mathrm{N}_{2}$ using cation exchanged ETS-10. It is important to note that the ability of ETS-10 to adsorb several gases depends on an adequate 
activation process (degassing by increase of the temperature) before adsorptive separation (PSA/TSA) or catalytic processes. In particular, humidity, carbon dioxide and nitrogen are the main atmospheric contaminants in this type of adsorbent.

Both these types of application (catalysis and separation) rely on close interactions between target molecules and the framework atoms, including the charge-balancing cations, and obtaining a more in-depth understanding of these interactions is crucial in this context. Computational methods can provide very useful insight into these systems. Indeed, due to the interesting properties of ETS-10 in many different applications, it is not surprising to find in the literature several computational works, using different approaches, performed with the aim of understanding the structural and spectroscopic properties, as well as the catalytic activity, of this class of materials. For example, de Man and Sauer [26] optimized at the Hartree-Fock (HF) level the atomic positions in several different cluster models of ETS-10 and their corresponding pure siliceous analogues. The calculations showed that titanium prefers a 4-fold coordination. Ching et al. [27] used the internal coordinates of ETS-10 crystal [2, 3] and performed an optimization of only the positions of the extra-framework cations using the local density approximation (LDA) based on the density functional theory (DFT). The possible locations of the alkali atoms were identified to occur inside the seven-member ring pores adjacent to the one-dimensional Ti-O-Ti-O- chains. While studying the optical properties of ETS-10 using DFT, Bordiga et al. [28] concluded that the unusual optical properties of the titanium silicate (ETS-10) molecular sieve are associated with the presence of atomically defined $-\mathrm{O}-\mathrm{Ti}-\mathrm{O}-\mathrm{Ti}-\mathrm{O}-$ chains that behave as linear quantum wires, while Zimmerman et al.[29] showed that band gap energies can be well represented with relatively small cluster models and that any asymmetry within the $-\mathrm{O}-\mathrm{Ti}-\mathrm{O}-$ chain does not affect the electronic structure of ETS-10. Other studies have analyzed the effect of 
changing the alkali metal cation [30] or substituting the framework transition metal [31] on the catalytic properties of ETS-10.

Spectroscopic techniques, sometimes complemented by DFT calculations, were used to investigate the structural properties of ETS-10 as well as the interactions of gas molecules with this material. For example, Guo et al. [32] studied the crystallization of ETS-10 by Raman spectroscopy combined with ${ }^{29} \mathrm{Si}$ Nuclear Magnetic Resonance (NMR), DFT calculations and scanning electron microscopy (SEM) imaging. They considered also the PBE functional and a single $-\mathrm{O}-\mathrm{Ti}-\mathrm{O}-$ chain model with three (3Ti) titanium atoms encapsulated in the supporting $\mathrm{SiO}_{2}$ framework, to calculate the vibrational frequencies, which were used to aid the assignment of the Raman bands. Vibrational spectroscopic studies were performed for the interaction of several gases (e.g. $\mathrm{CH}_{4}, \mathrm{H}_{2}, \mathrm{~N}_{2}, \mathrm{CO}, \mathrm{CO}_{2}, \mathrm{NO}$ and $\mathrm{H}_{2} \mathrm{O}$ ) in Na-ETS-10 [28, 33-38]. Zecchina et al. [33] studied by FTIR spectroscopy the adsorption of $\mathrm{H}_{2}, \mathrm{~N}_{2}, \mathrm{CO}$, and NO in M-ETS-10 materials $(\mathrm{M}=\mathrm{Na}$ or $\mathrm{K})$ with the aim of investigating the spectroscopic modifications induced on the vibrational modes of the sorbate molecules. They report the formation of $\mathrm{M}^{+} \cdots$ (sorbate) adducts involving mainly the cations located in the 12-membered ring channels. At high dosages and for $\mathrm{N}_{2}$ and $\mathrm{CO}$, they suggest that more than one molecule may interact with the same cation. The adducts give rise to IR absorption bands in the ranges of $4050-4150 \mathrm{~cm}^{-1}, 2331-2333 \mathrm{~cm}^{-1}$, 2148-2176 $\mathrm{cm}^{-1}$ and 1820-1900 $\mathrm{cm}^{-1}$, respectively, for $\mathrm{H}_{2}, \mathrm{~N}_{2}, \mathrm{CO}$ and NO. Llabrés i Xamena and Zecchina [38] and Kishima and Okubo [34] used $\mathrm{CO}_{2}$ and $\mathrm{CH}_{4}$, respectively, as probe molecules to evaluate the basicity of ETS-10 and they found that oxo-hydroxides contribute strongly to the basicity of ETS-10 as it happens for zeolites.

Despite their importance, however, the interaction of atmospheric gas molecules with ETS-10 having extra framework cations was not studied thoroughly. The present study aims at 
providing an atomic level knowledge about adsorption in this class of materials. For that purpose, DFT approaches were used to study the interaction of three types of molecules (polar, quadrupolar, and apolar type) with a finite cluster model of ETS-10 having extra-framework sodium ions (Na-ETS-10). It is thought that the DFT results for the interactions of $\mathrm{H}_{2} \mathrm{O}, \mathrm{H}_{2}, \mathrm{CH}_{4}$, $\mathrm{CO}_{2}$ and $\mathrm{N}_{2}$ in ETS-10 will be very important for the understanding of ETS-10 materials and will bring a theoretical background about their activation, a crucial prerequisite for their use as adsorbents or catalysts.

\section{Computational methods}

Plane-wave electronic structure calculations employing periodically repeated unit cells of ETS materials are computationally expensive due to the large sizes of their crystallographic cells [39]. Therefore, in the present work, we have considered the cluster approach and Gaussian type orbitals (GTOs) to model the structure of ETS-10. The initial atomic coordinates of the cluster model of ETS-10 were taken from the experimental crystallographic data [40]. The crystalline structure of ETS-10 (Figure 1) belongs to the $P 41$ space group and the lattice parameters are $a=$ $b=7.425 \AA$ and $\mathrm{c}=27.08 \AA$. The highlighted portion in Figure $1 \mathrm{~b}$, ball and stick representation of the single crystal structure contains a single $\mathrm{TiO}_{2}$ chain encapsulated in the supporting $\mathrm{SiO}_{2}$ framework. Figure 1a represents the model used for the QM investigation of gas sorption in ETS-10. It consists of a small cluster model containing two $\mathrm{Ti}$ (2Ti) atoms within the $\square \mathrm{O} \square \mathrm{Ti} \square \mathrm{O} \square \mathrm{Ti} \square \mathrm{O} \square$ chain and having a half portion of the 12-MR (12-member ring) with the extra framework sodium ions. The ETS-10 cluster model was terminated with hydroxyl groups. The terminating $\mathrm{H}$ atoms were placed at the same bond angles and dihedral angles as the

corresponding Si or Ti atom in the extended crystal structure, and at a bond distance of $0.965 \AA$, 
which is a typical value for this type of materials [41]. The initial positions of the cations employed to neutralize the system were taken from Wang and Jacobson [40].

(a)

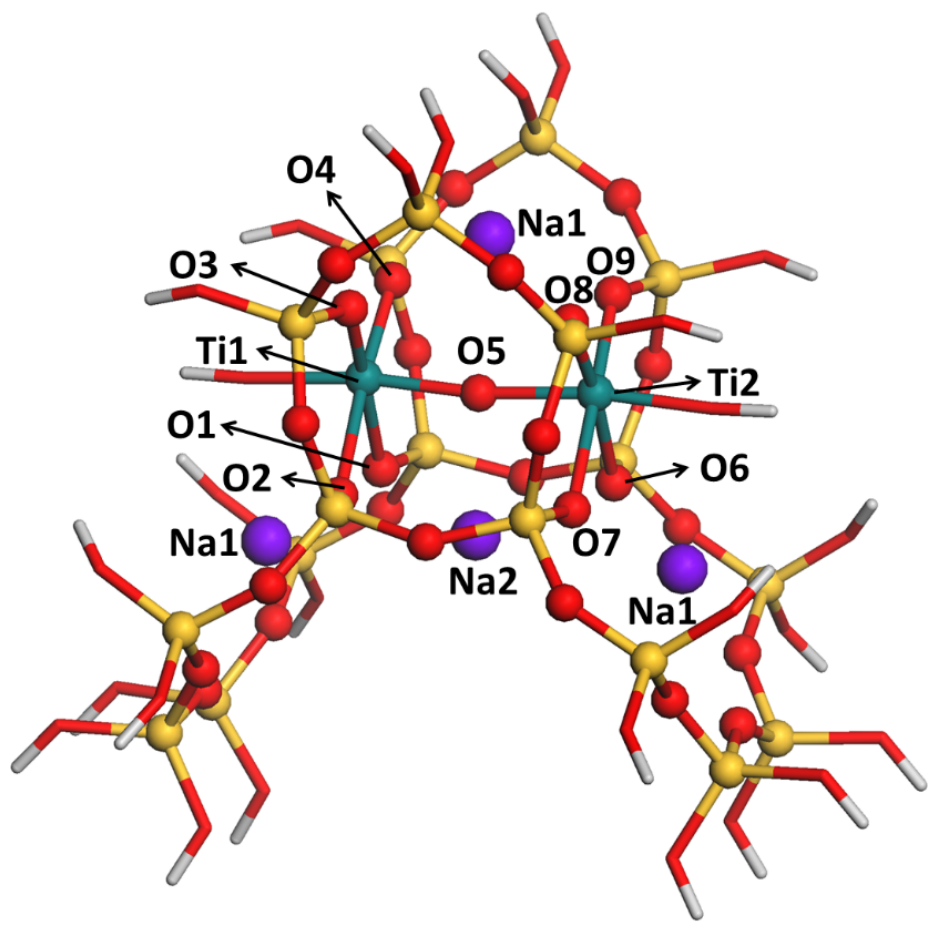

(b)

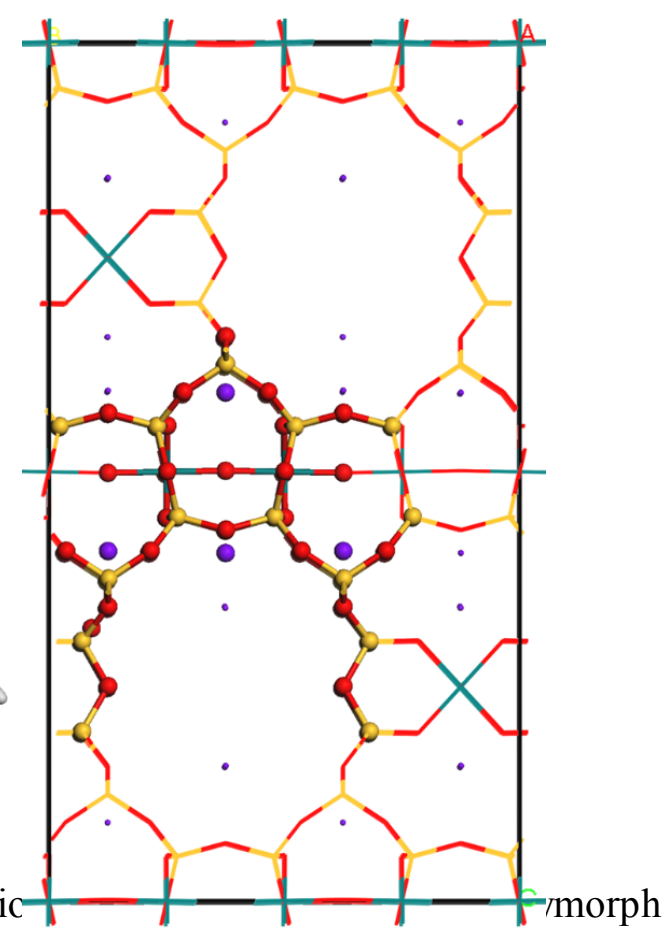

Figure 1. View of the cluster model (a) cut from the peric $\mathrm{B}$ from ref. [2]) shown in (b). The spheres in (a) represent atoms tully optımızed while sticks represent frozen atoms at their periodic positions. Note that terminal Si atoms were replaced by $\mathrm{H}$ in (a). Color code is: Bluish-green for $\mathrm{Ti}$, yellow for $\mathrm{Si}$, red for $\mathrm{O}$, violet for $\mathrm{Na}$ and white for H.

The cluster model has been chosen to model the interactions of the sorbates with the cations as well as with the $\square \mathrm{O} \square \mathrm{Ti} \square \mathrm{O} \square$ chains in the large channels of ETS-10. The structural changes and adsorption enthalpies for the different gases interacting with Na-ETS-10 were calculated at the DFT level with the Gaussian 09 code [42]. The energy of interaction, $E_{\text {int, }}$ was calculated as $E_{\text {int }}=E_{\text {sorbate-adsorbent }}-E_{\text {adsorbent }}-E_{\text {sorbate, }}$ where $E_{\text {adsorbent }}$ is the total energy of the 
isolated cluster model shown in Figure 1a, $E_{\text {sorbate }}$ is the total energy in vacuum of the sorbate (e.g. $\mathrm{H}_{2}, \mathrm{~N}_{2}, \mathrm{CO}_{2}, \mathrm{CH}_{4}$ or $\mathrm{H}_{2} \mathrm{O}$ ) and $E_{\text {sorbate-adsorbent }}$ is the total energy of the system, with the sorbate interacting with the cluster model. Thus, in the present notation, negative values for the energy of interaction mean favorable adsorption. The enthalpies of interaction at $T=0 \mathrm{~K}$ and 298.15 K were also obtained in this work by the inclusion of thermal corrections taken from the calculation of vibrational frequencies, which were also used to characterize all the structures as true minima on the potential energy surface. The geometries, the energies and the enthalpies of interaction include the basis set superposition error (BSSE) corrections calculated with the counterpoise method [43]. The structures of the different systems were fully optimized with the exception of the terminating hydroxyl groups in the NaETS-10 model, which were held fixed for a better representation of the rigid crystalline structure. In the case of the sorbate-adsorbent system, the sorbate molecule was initially positioned close to the Na2 cation, which is identified in Figure 1a.

This work is divided in two parts: In the first part, a DFT study was carried out for the interaction of methane with the Na-ETS-10cluster model using several different exchangecorrelation functionals included in the Gaussian 09 code, namely, B3LYP[44, 45] , B3PW91[44, 46], PBE[47, 48] , BP86[49, 50] , B97-D [51] , M06-L[52], M06 [52, 53], M06-2X [53], and M06-HF [53], and using the 6-31G(d,p) [54, 55]all-electron basis set for all the atoms. Experimental data available for the methane-Na-ETS-10 system was used to benchmark the computed enthalpies of interaction and to select the most interesting exchange-correlation functional to study molecular adsorption in NaETS-10. Then, in the second part, the selected functional was used to study the interaction of the other gaseous molecules with Na-ETS-10. The role of diffuse functions in the description of the interaction of the five molecules with NaETS- 
10 was also analyzed by further calculations employing the $6-31++\mathrm{G}(\mathrm{d}, \mathrm{p})$ basis set[56].To reduce the computational expense, diffuse functions were only considered for the atoms in the sorbate molecule, in the central $\mathrm{Na}$ cation $(\mathrm{Na} 2)$, and in the framework oxygen atoms neighboring the $\mathrm{Na} 2$ cation, i.e., which correspond to the atoms in the sorbate and to atoms labeled $\mathrm{O} 1, \mathrm{O} 2, \mathrm{O} 5, \mathrm{O} 6, \mathrm{O} 7$ and $\mathrm{Na} 2$ in Figure 1a.

\section{Results and Discussion}

\subsection{Structure of the bare Na-ETS-10 model}

Selected geometrical parameters for the optimized structure of the Na-ETS-10 cluster model are reported in Table 1. The most important aspect to check is the position of the sodium cations neighboring the large 12-MR channel, i.e., those interacting with the $\square \mathrm{O} \square \operatorname{Ti} \square \mathrm{O} \square$ chain and labeled in Figure 1 as $\mathrm{Na} 1$ and $\mathrm{Na} 2$, since these cations are expected to have a crucial role in the local geometry of the ETS-10 framework and in the strength of the sorbate-substrate interaction. According to Wang and Jacobson, [40] the Na2 cation is coordinated to five oxygen atoms at $2.57-2.62 \AA$ while Na1 is coordinated to eight oxygen atoms at distances $2.50-2.99 \AA$. Table 1 reports the range of interatomic distances in the ETS-10 cluster model calculated with the nine different exchange-correlation functionals considered in this work. From a quick inspection, it is seen that the range of distances calculated in this work, with several different DFT approaches and the $2 \mathrm{Ti}$ model shown in Figure 1a, is similar to that reported by Zimmerman et al [29] using a 5Ti model and the ONIOM(DFT:MM) approach. Additionally, the data calculated in this work is in satisfactory agreement with the single crystal X-ray diffraction data taken from ref. [40]. However, it should be noted that the calculations predict the sodium ions to be closer to the framework than the X-ray diffraction experiments, but this can be explained to some extent by the presence of disordered space-filling species, such as $\mathrm{H}_{2} \mathrm{O}$ 
molecules, in the structure studied experimentally, which are not being considered in the computational studies. The consideration of such species is less relevant for the purposes of the present computational work since ETS-10 is activated by heating for use in adsorption or in catalysis and, therefore, any adsorbed molecules are evacuated from the material during this process. Additional data for are provided as Supporting Information.

Table 1. Comparison of selected DFT geometrical parameters for the bare Na-ETS-10 cluster model with the corresponding experimental and ONIOM(DFT:MM) data taken from the literature.

\begin{tabular}{|c|c|c|c|}
\hline Parameter $^{\mathbf{a}}$ & Exptl. [40] $^{\text {ONIOM method [29] }}$ & DFT/6-31G(d,p $^{\mathbf{b}}$ \\
\hline Tix-Oy & $1.99 \pm 0.01$ & $1.91-2.13$ & $1.86-2.13$ \\
\hline Tix-O5 & $1.872 \pm 0.001$ & 1.94 & $1.82-1.88$ \\
\hline $\mathrm{Na} 2-\mathrm{O} z$ & $2.57 \pm 0.01$ & & $2.36-2.46$ \\
\hline $\mathrm{Na} 2-\mathrm{O} 5$ & $2.62 \pm 0.03$ & & $2.22-2.29$ \\
\hline Ti1-O5-Ti2 & 177.9 & & $171.9-173.8$ \\
\hline
\end{tabular}

${ }^{a}$ Atomic labeling in Figure 1 with $x=1$ or $2, y=1-4$ or $6-9, z=1,2,6$ or 7 ; distances in $\AA$ and angles in degrees. ${ }^{b}$ Range of results calculated in this work with different functionals.

\subsection{Adsorption of Methane in Na-ETS-10}

In ETS-10, the cations act as electron-pair acceptors toward the framework oxygen atoms or toward the sorbates. The experimental results (for example, single crystal $[2,40]$, multi nuclear NMR [5], vibrational spectra [32, 33, 35, 36, 38] , TPD [9], adsorption [15] and catalysis $[8,30,57]$ studies) disclosed that the cations $\mathrm{Na} 2$, which are less coordinated than cations of the type Na1, would be the primary sites for interaction with guest molecules in the 12 MR of ETS10. Recent calculations on the interaction of acetylene with Na-ETS-10 showed that the 
preferential sites for adsorption were the $\mathrm{Na}^{+}$ions with which the acetylene forms $\pi$-complexes [57].

Table 2. Optimized sorbate to cation distances $\left(\mathrm{d}\left(\mathrm{Na}^{+} \ldots \mathrm{C}\right), \AA\right)$, interaction energies $(\Delta E, \mathrm{~kJ} / \mathrm{mol})$ and interaction enthalpies at $T=298.15 \mathrm{~K}\left(\Delta H^{298.15 \mathrm{~K}}, \mathrm{~kJ} / \mathrm{mol}\right)$ calculated at the DFT $/ 6-31 \mathrm{G}(\mathrm{d}, \mathrm{p})$ level of theory for $\mathrm{CH}_{4}$ adsorption at the 12-MR of Na-ETS-10. ${ }^{a}$

\begin{tabular}{|l|c|c|c|}
\hline DFT approach & $\mathbf{d}\left(\mathbf{N a}^{+} \cdots \mathbf{C}\right)$ & $\boldsymbol{\Delta}$ & $\boldsymbol{\Delta} \boldsymbol{H}^{\mathbf{2 9 8 . 1 5} \mathbf{K}}$ \\
\hline B3LYP & 2.93 & $-2.5(-11.9)$ & $2.1(-7.3)$ \\
\hline B3PW91 & 3.04 & $5.8(-5.7)$ & $10.3(-1.1)$ \\
\hline B97-D & 2.67 & $-44.3(-56.0)$ & $-37.5(-49.2)$ \\
\hline BP86 & 3.27 & $-13.0(-25.1)$ & $-6.3(-18.6)$ \\
\hline M06-L & 2.88 & $-27.7(-34.2)$ & $-20.9(-27.8)$ \\
\hline M06 & 2.84 & $-23.7(-33.2)$ & $-19.1(-28.6)$ \\
\hline M06-2X & 3.00 & $-22.9(-34.1)$ & $-18.4(-27.4)$ \\
\hline M06-HF & 2.86 & $-22.1(-33.5)$ & $-18.3(-27.3)$ \\
\hline PBE & 2.89 & $-8.2(-20.0)$ & $-3.8(-15.6)$ \\
\hline
\end{tabular}

${ }^{\mathrm{a}}$ Available experimental enthalpies of interaction are: $-21.4 \mathrm{~kJ} / \mathrm{mol}$ (Toth model, ref.[17]), $-21.0 \mathrm{~kJ} / \mathrm{mol}$ (unilan model, ref.[17]), $-20.8 \mathrm{~kJ} / \mathrm{mol}$ (virial three constants model, ref. [17]), $-22.9 \mathrm{~kJ} / \mathrm{mol}$ (virial three constants model, ref.[58]), $-23.3 \mathrm{~kJ} / \mathrm{mol}$ (Toth model, ref.[22]). Energies and enthalpies in parentheses do not include BSSE corrections.

The adsorption of molecules by materials involves in many cases weak interactions dominated by dispersion that constitute a challenge for standard DFT approaches [59, 60]. Herewith, the experimental range of values for the enthalpy of interaction between the apolar methane molecule and Na-ETS-10 was used to benchmark several different functionals. The experimental enthalpies of interaction are included in the interval from $-20.8 \mathrm{~kJ} / \mathrm{mol}$ to -23.3 $\mathrm{kJ} / \mathrm{mol}$ and were deduced from the fit of Toth, unilan or virial three constants models to the adsorption data obtained with volumetric systems in temperature ranges around $T=298.15 \mathrm{~K}[17$, 
$22,58]$. Note that the experimental isosteric enthalpies were obtained with the ClausiusClapeyron relation, with expected errors of about 3-5\% [61, 62]. The enthalpies of interaction at $T=298.15 \mathrm{~K}$, calculated at the DFT/6-31G(d,p) level of theory, with and without corrections for the BSSE, are given in Table 2. As it can be seen, BSSE corrections are quite large, and should be considered in order to obtain reliable results.

The enthalpies calculated with the family of M06 functionals are in much better agreement with the experimental results than the enthalpies calculated with the B3LYP, B3PW91, BP86 and PBE approaches. This is a consequence of the inclusion of dispersion interactions in these functionals, which are absent in the other, widely used, DFT approaches [59]. Note, however, that the B97-D functional which includes dispersion but in a quite empirical way[59] leads to significant overestimation of the enthalpy for methane interacting with Na-ETS-10 $(\sim 15$ $\mathrm{kJ} / \mathrm{mol}$ ).Looking in detail to the enthalpies calculated with the four different M06 functionals we can conclude that the local version (M06-L) yields the best agreement with the available experimental results, in line with previous suggestions that M06 functionals with larger percentages of Hartree-Fock exchange, i.e., M06-2X and M06-HF, are less interesting for systems having transition metal elements [53]. It also corroborates recent findings where this functional was shown to provide very good interaction energies for challenging systems dominated by dispersion forces, namely, interaction of $\mathrm{CO}$ with the (111) surfaces of $\mathrm{Rh}, \mathrm{Pt}, \mathrm{Cu}$, $\mathrm{Ag}$ and $\mathrm{Pd}$ [63], adsorption of benzene, pyridine, thymine and cytosine on the $\mathrm{Au}(111)$ surface [64] or interaction of water with the CuBTC metal organic framework [65]. The fact that the M06-L/6-31G(d,p) enthalpy for methane interaction with the Na-ETS-10 model is included in the interval defined by the experimental results is very encouraging, and we have decided to use the same approach to study the interaction of other molecules with Na-ETS-10 (c.f. next section). 
Note also that the M06-L result for methane is significantly improved with respect to the Grand Canonical Monte Carlo (GCMC) isosteric heat of adsorption at $T=298.15 \mathrm{~K}$ of $-28 \mathrm{~kJ} / \mathrm{mol}$ reported by Gallo et al. [66]. The calculated sodium to methane distances, $d\left(\mathrm{Na}^{+} \cdots \mathrm{C}\right)$, are between $2.84 \AA$ and $3.04 \AA$, which are similar to the distances reported by Guo et al. [57] for acetylene interaction with Na-ETS-10, i.e., $2.76 \AA$ and $2.87 \AA$ for the two $\mathrm{C}$ atoms in HCCH.The calculated NPA (Natural Population Analysis) charges show that the methane molecule becomes slightly positively charged $(+0.019 e)$, while the charge of the Na2 cation is $0.082 e$ less positive than in the bare model (Supporting Information), i.e. upon the formation of the sorbate-substrate complex, the charge gain in $\mathrm{Na} 2$ results from the interaction with the sorbate and also from neighboring $\mathrm{Na} 1$ atoms.

\subsection{Adsorption of Other Gases in ETS-10}

The M06-L functional was used in the optimization of the geometries and calculation of the energies and enthalpies corresponding to the interactions of the polar $\left(\mathrm{H}_{2} \mathrm{O}\right)$, quadrupolar $\left(\mathrm{CO}_{2}\right.$ and $\left.\mathrm{N}_{2}\right)$, and apolar $\left(\mathrm{H}_{2}\right)$ atmospheric gases with Na-ETS-10. The calculations were performed with two different types of basis sets, the 6-31G(d,p) basis set used in the calculations reported in the previous section, and the $6-31++G(d, p)$ basis set, which includes a set of diffuse functions in all the atoms.

The configurations optimized at the M06-L/6-31++G(d,p)level of theory for the $\mathrm{CH}_{4}, \mathrm{~N}_{2}$, $\mathrm{H}_{2}, \mathrm{CO}_{2}$ and $\mathrm{H}_{2} \mathrm{O}$ molecules interacting with the Na-ETS-10 model are depicted in Figures 2, 3, 4, 5 and 6, respectively and additional structural details are provided as Supporting Information. As found for methane, the $\mathrm{H}_{2} \mathrm{O}, \mathrm{CO}_{2}, \mathrm{H}_{2}$, and $\mathrm{N}_{2}$ sorbates are interacting with the $\mathrm{Na} 2$ ion (c.f. 
Figure 1) at distances of $2.36 \AA, 2.51 \AA, 2.70 \AA$ and $2.75 \AA$ (Figures 3 - 6), respectively. Similar distances were computed with the 6-31G(d,p) basis set, e.g., $2.36 \AA, 2.52 \AA, 2.61 \AA$ and $2.72 \AA$, respectively, suggesting that geometries are well described with the basis set without diffuse functions and that the most important difference is in the calculated energies [67]. From the data compiled in Table 3, it is found that the sorbates are not affecting too much the position of the $\mathrm{Na} 2$ ion, which despite being less coordinated to the framework oxygen atoms than Na1, moves only slightly from its original location in the bare Na-ETS-10 model. This is quite interesting, since the interaction enthalpies calculated for the five different sorbates (see Table 4) span a range of values between $-12.2 \mathrm{~kJ} / \mathrm{mol}\left(\mathrm{H}_{2}\right)$ and $-60.6 \mathrm{~kJ} / \mathrm{mol}\left(\mathrm{H}_{2} \mathrm{O}\right)$, i.e., the interaction energy for water in Na-ETS-10 is approximatelly 6 times larger (i.e. stronger) than that calculated for hydrogen. Although water does cause the largest displacement of $\mathrm{Na} 2$ from the original crystallographic position (the Na2-O5 distance in the case of water adsorption, i.e., $2.29 \AA$, is slightly increased by $\sim 0.05 \AA$ ), this is a very small effect, and is practically absent with the other less polar sorbates (the other four cases have Na2-O5 distances of 2.24-2.25 $\AA$ ).Additionally, upon interaction with the $\mathrm{Na} 2$ position, total charges in the sorbate molecules are slightly positive, with NPA values of $0.081,0.026,0.035$ and $0.038 e$ respectively for $\mathrm{N}_{2}, \mathrm{H}_{2}, \mathrm{CO}_{2}$ and $\mathrm{H}_{2} \mathrm{O}$ species, and the $\mathrm{Na} 2$ cation gains some electron charge upon interaction with these adsorbates, respectively, $0.100,0.061,0.061$ and $0.060 e$ (Supporting Information).

The calculated enthalpies at $T=298.15 \mathrm{~K}$ for nitrogen and carbon dioxide adsorption on NaETS-10 compare well with the experimental isosteric heats available in the literature. The differences between the calculated and experimental data are $1.3 \mathrm{~kJ} / \mathrm{mol}$ and $6.8 \mathrm{~kJ} / \mathrm{mol}$, respectively. Note that the experimental result for nitrogen was derived from experimental studies where air instead of nitrogen was used [25], and that in the case of $\mathrm{CO}_{2}$ the data points 
used to derive the isosteric heats of adsorption were obtained at temperatures well above 298.15 $\mathrm{K}$ [22]. The good agreement between calculated enthalpies of interaction and experimental heats of adsorption found for methane, nitrogen and carbon dioxide gives us confidence about the quality of the calculated enthalpies for hydrogen and water adsorption in Na-ETS-10, for which experimental heats of adsorption are not available. The M06-L enthalpies of interaction at $T=298.15 \mathrm{~K}$ for hydrogen and carbon dioxide in Na-ETS-10 are not far from the GCMC isosteric heats of adsorption, at the same temperature, reported by Gallo et al. [66], with values of -9 and $37 \mathrm{~kJ} / \mathrm{mol}$, respectively.

Table 3. Sodium to adsorbate and sodium to framework oxygens distances $(\AA)$ optimized at the M06-L/6-31++G(d,p) level of theory using BSSE corrections. ${ }^{\text {a }}$

\begin{tabular}{|c|c|c|c|c|c|c|}
\hline & Bare & $\mathrm{CH}_{4}$ & $\mathbf{N}_{2}$ & $\mathbf{H}_{2}$ & $\mathrm{CO}_{2}$ & $\mathrm{H}_{2} \mathrm{O}$ \\
\hline Na2-adsorbate ${ }^{b}$ & - & 2.88 & 2.75 & 2.70 & 2.51 & 2.36 \\
\hline $\mathrm{Na} 2-\mathrm{O} 1$ & 2.42 & 2.42 & 2.41 & 2.40 & 2.42 & 2.41 \\
\hline $\mathrm{Na} 2-\mathrm{O} 2$ & 2.42 & 2.42 & 2.43 & 2.43 & 2.46 & 2.49 \\
\hline $\mathrm{Na} 2-\mathrm{O} 5$ & 2.25 & 2.25 & 2.24 & 2.25 & 2.25 & 2.29 \\
\hline $\mathrm{Na} 2-\mathrm{O} 6$ & 2.42 & 2.42 & 2.42 & 2.41 & 2.42 & 2.44 \\
\hline $\mathrm{Na} 2-\mathrm{O} 7$ & 2.42 & 2.42 & 2.46 & 2.43 & 2.45 & 2.50 \\
\hline
\end{tabular}

${ }^{\mathrm{a}}$ Distances in the bare model are also provided for comparison purposes. ${ }^{\mathrm{b}}$ Nearest neighbor distances, except for methane where the Na2-C distance is given. 
Table 4. Comparison between the experimental isosteric heats of adsorption $\left(\Delta H^{\text {isosteric }}\right)$ and the calculated energies $(\Delta E)$ or enthalpies of interaction $\left(\Delta H^{\mathrm{T}} \mathrm{K}\right)$ at temperatures $T=0 \mathrm{~K}$ or $298.15 \mathrm{~K}$. All values in $\mathrm{kJ} / \mathrm{mol}^{\mathrm{a}}$

\begin{tabular}{|c|c|c|c|c|}
\hline Gas & $\boldsymbol{\Delta} \boldsymbol{H}^{\text {isosteric }}$ & $\boldsymbol{\Delta}$ & $\boldsymbol{\Delta} \boldsymbol{H}^{\mathbf{0}}$ & $\boldsymbol{\Delta} \boldsymbol{H}^{\mathbf{2 9 8 . 1 5} \mathbf{K}}$ \\
\hline $\mathrm{CH}_{4}$ & -20.8 to $-23.3[17,58]$ & $-27.4(-27.7)$ & $-20.2(-20.3)$ & $-20.8(-20.9)$ \\
\hline $\mathrm{N}_{2}$ & $-22.8^{\mathrm{b}}[25]$ & $-22.8(-26.7)$ & $-20.8(-24.9)$ & $-21.5(-25.5)$ \\
\hline $\mathrm{H}_{2}$ & & $-14.9(-12.8)$ & $-9.5(-7.7)$ & $-12.2(-10.4)$ \\
\hline $\mathrm{CO}_{2}$ & $-42.1[22]$ & $-39.5(-42.9)$ & $-36.4(-40.2)$ & $-35.3(-39.0)$ \\
\hline $\mathrm{H}_{2} \mathrm{O}$ & & $-66.7(-66.2)$ & $-59.1(-58.6)$ & $-60.6(-60.1)$ \\
\hline
\end{tabular}

${ }^{a}$ Data in parenthesis were calculated with the M06-L/6-31G(d,p) approach while the remaining values were obtained at the M06-L/6-31++G(d,p) level of theory; interaction energies and enthalpies include BSSE corrections. ${ }^{\mathrm{b}}$ Air adsorption.

The comparison of data in Tables 3 and 4 shows some correlation between the sorbate to sodium (Na2) distance and the enthalpy of interaction, with the exception of hydrogen, which can be explained by its smaller size when compared with the other four gases. As it can be seen in Table 3 and Figures 5 and 6, water and carbon dioxide bind closest to the sodium ion Na2 and are the gases having the largest interaction enthalpies, with water being the hardest among the studied species to remove from Na-ETS-10. 
(a)
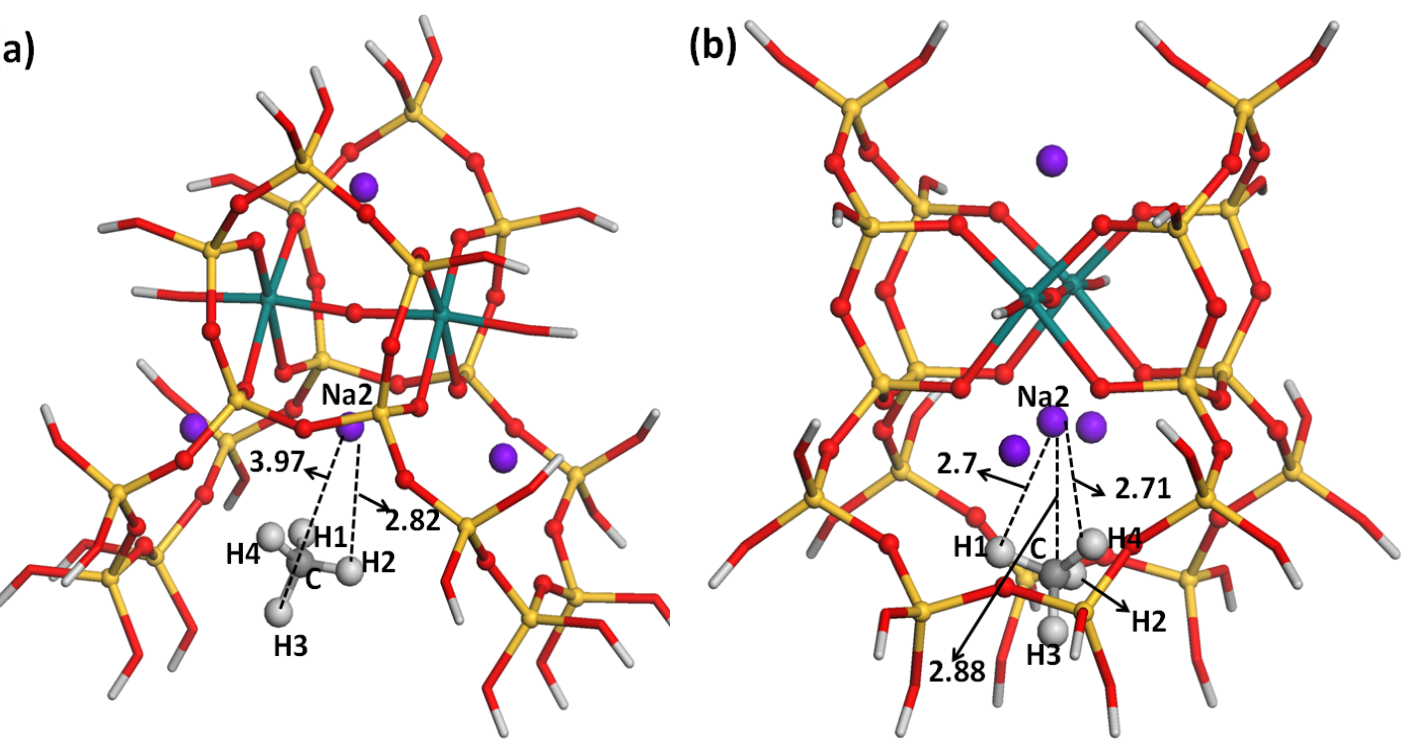

Figure 2. Configurations optimized with the $\mathrm{M} 06-\mathrm{L} / 6-31++\mathrm{G}(\mathrm{d}, \mathrm{p})$ approach and the counterpoise methodfor $\mathrm{CH}_{4}$, interacting with Na-ETS-10, viewed along directions parallel (a) and normal (b) to the -Ti-O-Ti- chain. Dashed lines show the distances between the sodium cation and each individual atom of the sorbate. Color code is the same as in Figure 1, plus grey for Carbon.
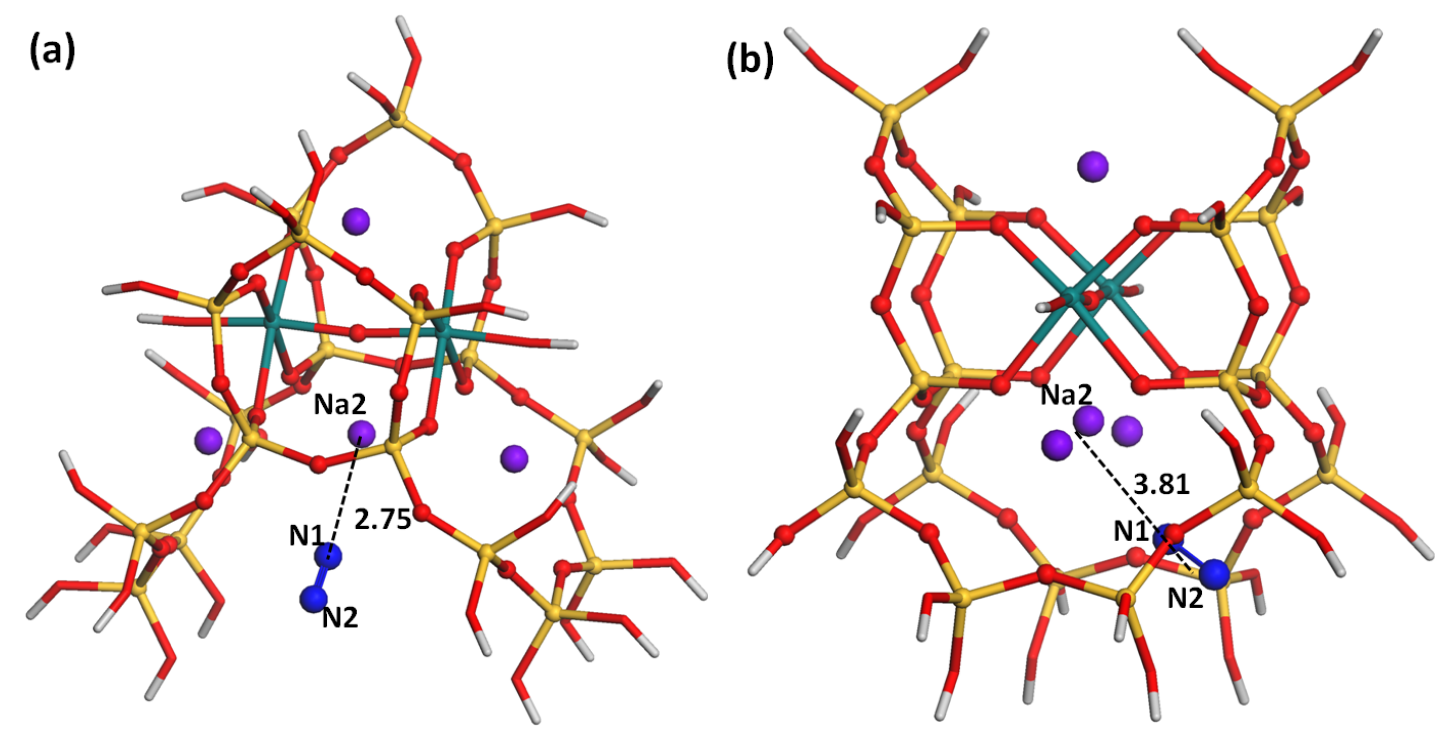

Figure 3. Configurations optimized with the M06-L/6-31++G(d,p) approach and the counterpoise methodfor $\mathrm{N}_{2}$ interacting with Na-ETS-10, viewed along directions parallel (a) and normal (b) to the $-\mathrm{Ti}-\mathrm{O}-\mathrm{Ti}-$ chain. Dashed lines show the distances between the sodium cation and each individual atom of the sorbate. Color code is the same as in Figure 1, plus blue for Nitrogen. 

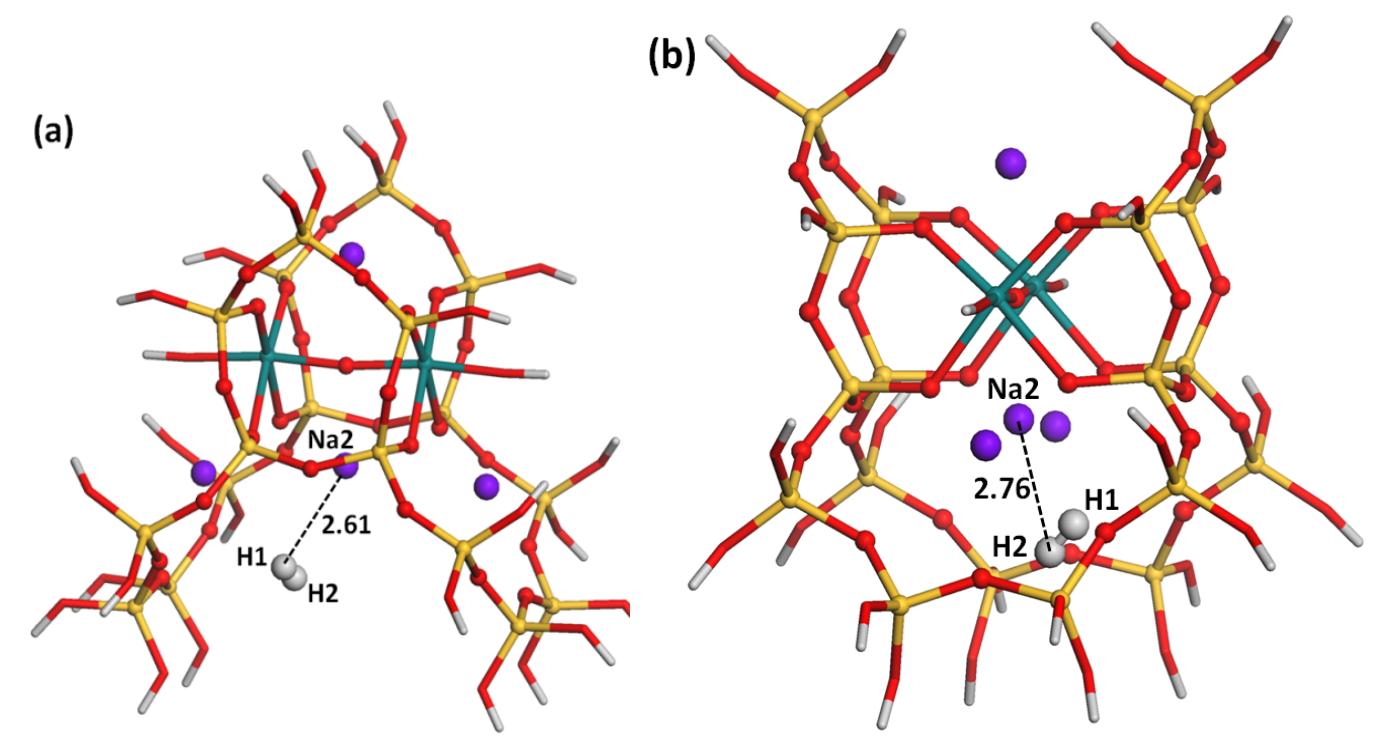

Figure 4. Configurations optimized with the $\mathrm{M} 06-\mathrm{L} / 6-31++\mathrm{G}(\mathrm{d}, \mathrm{p})$ approach and the counterpoise methodfor $\mathrm{H}_{2} \mathrm{H}_{2} \mathrm{O}$ interacting with Na-ETS-10, viewed along directions parallel (a) and normal(b) to the -Ti-O-Ti- chain. Dashed lines show the distances between the sodium cation and each individual atom of the sorbate. Color code is the same as in Figure 1.
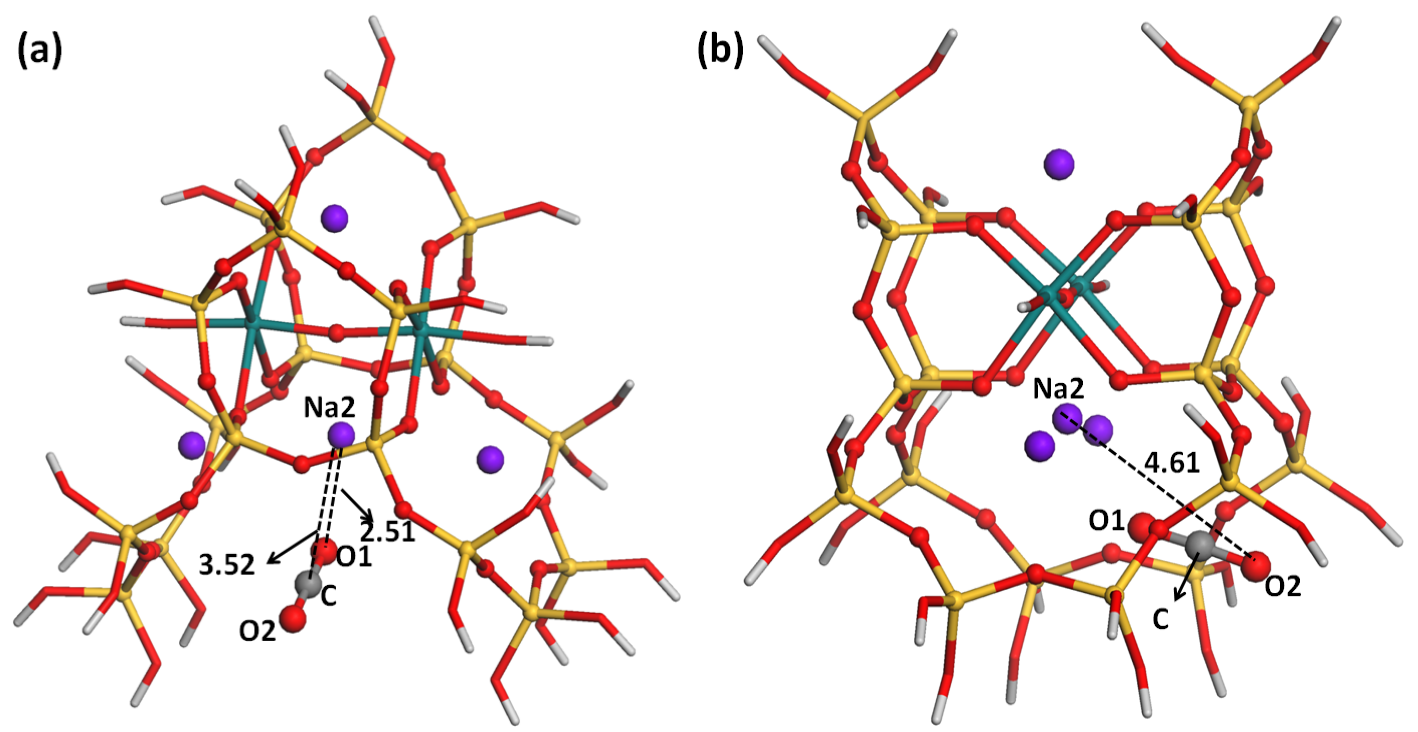

Figure 5. Configurations optimized with the $\mathrm{M} 06-\mathrm{L} / 6-31++\mathrm{G}(\mathrm{d}, \mathrm{p})$ approach and the counterpoise methodfor $\mathrm{CO}_{2}$ interacting with Na-ETS-10, viewed along directions parallel (a) and normal(b) to the - $\mathrm{Ti}-\mathrm{O}-\mathrm{Ti}-$ chain. Dashed lines show the distances between the sodium cation and each individual atom of the sorbate. Color code is the same as in Figure 1, plus grey for Carbon. 

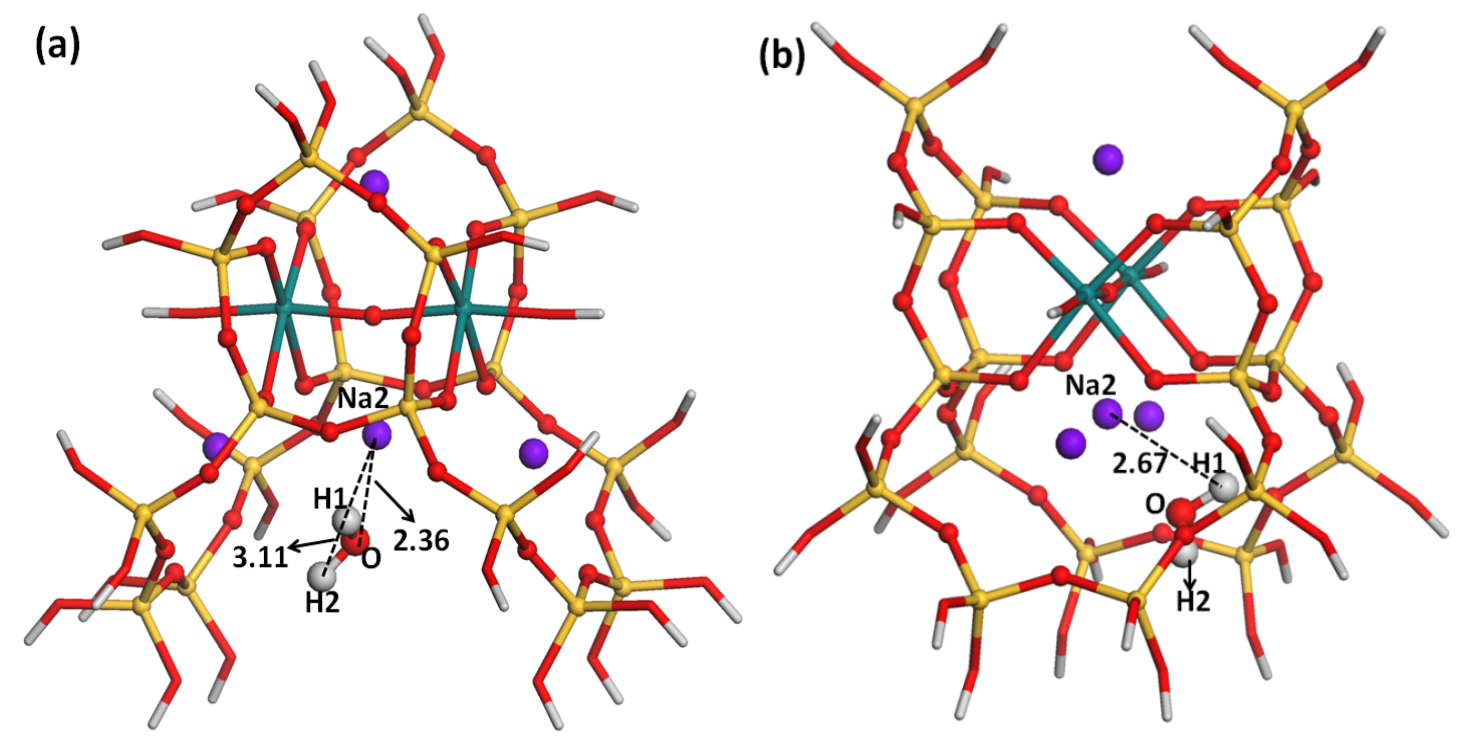

Figure 6. Configurations optimized with the $\mathrm{M} 06-\mathrm{L} / 6-31++\mathrm{G}(\mathrm{d}, \mathrm{p})$ approach and the counterpoise methodfor $\mathrm{H}_{2} \mathrm{O}$ interacting with Na-ETS-10, viewed along directions parallel (a) and normal (b) to the -Ti-O-Ti- chain. Dashed lines show the distances between the sodium cation and each individual atom of the sorbate. Color code is the same as in Figure 1.

Atmospheric gases are contaminants that can be found in this type of materials when exposed to air, so their regeneration for catalytic or sorption applications is a very important aspect. The present DFT study suggests that if Na-ETS-10 is used for catalysis, gas storage or gas separation, water will be an important contaminant since it presents a much higher interaction enthalpy than any of the other four atmospheric gases considered in this work.

\subsection{Vibrational Frequencies for Atmospheric Gases in ETS-10}

The calculated vibrational frequencies at the M06-L/6-31++G(d,p) level of theory for the optimized systems showed several peaks in the spectral regions that are characteristic of the Si-O stretching modes in $\mathrm{SiO}_{2}$, e.g. $917-987 \mathrm{~cm}^{-1}$, and of the Ti-O stretching modes in -Ti-O-Tichains, e.g. $\sim 630 \mathrm{~cm}^{-1}$, [57]. Several other vibrations are also in good agreement with other 
experimental results suggested to be characteristic for ETS-10 (e.g. vibrations at 1140, 1123, $1090,1032,882,750,731,665,610,555,515,490,456,440$, and $\left.434 \mathrm{~cm}^{-1}[68]\right)$. Selected vibrational frequencies calculated at the M06-L/6-31++G(d,p) level of theory for isolated and for adsorbed gases are compared with available experimental results in Tables 5 and 6 , respectively. As it is common practice, the calculated vibrational frequencies had to be scaled since most of the computational approaches yield vibrational frequencies that are generally larger than the experimentally observed frequencies [69]. The experimental vibrational frequencies with values above $1000 \mathrm{~cm}^{-1}$ for the five atmospheric gases considered in this work were used to optimize a scale factor for the M06-L/6-31++G(d,p) method. The optimal scale factor obtained by minimization of the sum of the differences between scaled and experimental vibrations is 0.949 which is not far from the scale factor reported by Truhlar and co-workers $(0.953)$ for the M06$\mathrm{L} / 6-31+\mathrm{G}(\mathrm{d}, \mathrm{p})$ combination and for a database consisting of 15 molecules [70]. As it can be seen in Table 6, scaled frequencies for the different sorbate molecules compare well with available IR absorption bands [33, 36-38]. This confirms that the experimental vibrations are due to the formation of $\mathrm{Na}^{+} \cdots$ adsorbate $\left(\mathrm{CH}_{4}, \mathrm{~N}_{2}, \mathrm{H}_{2}, \mathrm{CO}_{2}\right.$ and $\left.\mathrm{H}_{2} \mathrm{O}\right)$ adducts with $\mathrm{Na}$ cations located in the 12-membered channels, and that the model with two titanium (2Ti) and four extra-framework sodium ions at their two cation locations is able to capture correctly the physics of the adsorption process in ETS-10 materials. 
Table 5. Comparison of relevant calculated and experimental vibrational frequencies $\left(\mathrm{cm}^{-1}\right)$ for the isolated gas molecules.

\begin{tabular}{|c|c|c|c|c|}
\hline \multirow{2}{*}{ Molecule } & \multicolumn{2}{|c|}{ Calculated $^{\mathrm{a}}$} & \multicolumn{2}{|c|}{ Experimental } \\
\hline & Unscaled & Scaled & Band & Ref. \\
\hline \multirow{4}{*}{$\mathrm{CH}_{4}$} & $3196\left(v_{\mathrm{C}-\mathrm{H}, \text { assym }}\right)$ & $3033\left(v_{\mathrm{C}-\mathrm{H}, \text { assym }}\right)$ & $3019\left(v_{\mathrm{C}-\mathrm{H}, \text { assym }}\right)$ & \multirow{4}{*}[71]{} \\
\hline & $3046\left(v_{\mathrm{C}-\mathrm{H}, \mathrm{sym}}\right)$ & $2890\left(v_{\mathrm{C}-\mathrm{H}, \mathrm{sym}}\right)$ & $2917\left(v_{\mathrm{C}-\mathrm{H}, \mathrm{sym}}\right)$ & \\
\hline & $1550\left(\delta_{\mathrm{H}-\mathrm{C}-\mathrm{H}}\right)$ & $1471\left(\delta_{\mathrm{H}-\mathrm{C}-\mathrm{H}}\right)$ & $1534\left(\delta_{\mathrm{H}-\mathrm{C}-\mathrm{H}}\right)$ & \\
\hline & $1323\left(\delta_{\mathrm{H}-\mathrm{C}-\mathrm{H}}\right)$ & $1255\left(\delta_{\mathrm{H}-\mathrm{C}-\mathrm{H}}\right)$ & $1306\left(\delta_{\mathrm{H}-\mathrm{C}-\mathrm{H}}\right)$ & \\
\hline $\mathrm{N}_{2}$ & $2433\left(v_{\mathrm{N}-\mathrm{N}}\right)$ & $2309\left(v_{\mathrm{N}-\mathrm{N}}\right)$ & $2331\left(v_{\mathrm{N}-\mathrm{N}}\right)$ & [72] \\
\hline $\mathrm{H}_{2}$ & $4379\left(v_{\mathrm{H}-\mathrm{H}}\right)$ & $4155\left(v_{\mathrm{H}-\mathrm{H}}\right)$ & $4155\left(v_{\mathrm{H}-\mathrm{H}}\right)$ & [72] \\
\hline \multirow{3}{*}{$\mathrm{CO}_{2}$} & $2479\left(v_{\mathrm{O}-\mathrm{C}-\mathrm{O}, \text { assym }}\right)$ & $2352\left(v_{\mathrm{O}-\mathrm{C}-\mathrm{O}, \text { assym }}\right)$ & $2349\left(v_{\mathrm{O}-\mathrm{C}-\mathrm{O}, \text { assym }}\right)$ & \multirow{3}{*}[71]{} \\
\hline & $1380\left(v_{\mathrm{O}-\mathrm{C}-\mathrm{O}, \mathrm{sym}}\right)$ & $1309\left(v_{\mathrm{O}-\mathrm{C}-\mathrm{O}, \mathrm{sym}}\right)$ & $1337\left(v_{\mathrm{O}-\mathrm{C}-\mathrm{O}, \mathrm{sym}}\right)$ & \\
\hline & $665\left(\delta_{\mathrm{O}-\mathrm{C}-\mathrm{O}}\right)$ & $665\left(\delta_{\mathrm{O}-\mathrm{C}-\mathrm{O}}\right)$ & $667\left(\delta_{\mathrm{O}-\mathrm{C}-\mathrm{O}}\right)$ & \\
\hline \multirow{3}{*}{$\mathrm{H}_{2} \mathrm{O}$} & $4009\left(v_{\mathrm{O}-\mathrm{H}}\right)$ & $3804\left(v_{\mathrm{O}-\mathrm{H}}\right)$ & $3756\left(v_{\mathrm{O}-\mathrm{H}}\right)$ & \multirow{3}{*}[71]{} \\
\hline & $3873\left(v_{\mathrm{O}-\mathrm{H}}\right)$ & $3675\left(v_{\mathrm{O}-\mathrm{H}}\right)$ & $3657\left(v_{\mathrm{O}-\mathrm{H}}\right)$ & \\
\hline & $1651\left(\delta_{\mathrm{H}-\mathrm{O}-\mathrm{H}}\right)$ & $1567\left(\delta_{\mathrm{H}-\mathrm{O}-\mathrm{H}}\right)$ & $1595\left(\delta_{\mathrm{H}-\mathrm{O}-\mathrm{H}}\right)$ & \\
\hline
\end{tabular}

${ }^{\mathrm{a}} \mathrm{M} 06-\mathrm{L} / 6-31++\mathrm{G}(\mathrm{d}, \mathrm{p})$ level of theory; scale factor for vibrations above $1000 \mathrm{~cm}^{-1}$ is 0.949 while vibrations below are unscaled. 
Table 6. Comparison of relevant calculated and experimental vibrational frequencies $\left(\mathrm{cm}^{-1}\right)$ for different adsorbed molecules in Na-ETS-10.

\begin{tabular}{|c|c|c|c|c|}
\hline \multirow{2}{*}{ Sorbate } & \multicolumn{2}{|c|}{ Calculated $^{\mathbf{a}}$} & \multicolumn{2}{|c|}{ Experimental } \\
\hline & Unscaled & Scaled & Bands & Ref. \\
\hline $\mathrm{CH}_{4}$ & $\begin{array}{c}3179\left(v_{\mathrm{C}-\mathrm{H}}\right), \\
3171\left(v_{\mathrm{C}-\mathrm{H}}\right), \\
3031\left(v_{\mathrm{C}-\mathrm{H}}\right), \\
1318\left(\delta_{\mathrm{H}-\mathrm{C}-\mathrm{H}}\right)\end{array}$ & $\begin{array}{c}3016\left(v_{\mathrm{C}-\mathrm{H}}\right), \\
3009\left(v_{\mathrm{C}-\mathrm{H}}\right), \\
\mathbf{2 8 7 6}\left(v_{\mathrm{C}-\mathrm{H}}\right), \\
1250\left(\delta_{\mathrm{H}-\mathrm{C}-\mathrm{H}}\right)\end{array}$ & $\mathbf{2 8 8 5}, 2893,2900\left(v_{\mathrm{C}-\mathrm{H}}\right)^{\mathrm{b}}$ & [34] \\
\hline $\mathrm{N}_{2}$ & $2431\left(v_{\mathrm{N}-\mathrm{N}}\right)$ & $2307\left(v_{N-N}\right)$ & $2333\left(v_{N-N}\right)$ & [33] \\
\hline $\mathrm{H}_{2}$ & $4329\left(v_{\mathrm{H}-\mathrm{H}}\right)$ & $4107\left(v_{\mathrm{H}-\mathrm{H}}\right)$ & $4113,4107\left(v_{\mathrm{H}-\mathrm{H}}\right)^{\mathrm{c}}$ & [33] \\
\hline $\mathrm{CO}_{2}$ & $\begin{array}{c}2486\left(v_{\mathrm{O}-\mathrm{C}-\mathrm{O}}\right), \\
1379\left(v_{\mathrm{O}-\mathrm{C}-\mathrm{O}}\right), \\
1208\left(v_{\mathrm{O}-\mathrm{C}-\mathrm{O}}\right), \\
665\left(\delta_{\mathrm{O}-\mathrm{C}-\mathrm{O}}\right)\end{array}$ & $\begin{array}{c}2359\left(v_{\mathrm{O}-\mathrm{C}-\mathrm{O}}\right), \\
1308\left(v_{\mathrm{O}-\mathrm{C}-\mathrm{O}}\right), \\
1146\left(v_{\mathrm{O}-\mathrm{C}-\mathrm{O}}\right), \\
665\left(\delta_{\mathrm{O}-\mathrm{C}-\mathrm{O}}\right)\end{array}$ & $\begin{array}{c}2353\left(v_{\mathrm{O}-\mathrm{C}-\mathrm{O}}\right) \\
1690,1365^{\mathrm{d}} \\
1381,1274^{\mathrm{e}}\end{array}$ & [38] \\
\hline $\mathrm{H}_{2} \mathrm{O}$ & $\begin{array}{c}3932\left(v_{\mathrm{O}-\mathrm{H}}\right) \\
3714\left(v_{\mathrm{O}-\mathrm{H}}\right) \\
1698\left(\delta_{\mathrm{H}-\mathrm{O}-\mathrm{H}}\right)\end{array}$ & $\begin{array}{c}3731\left(v_{\mathrm{O}-\mathrm{H}}\right), \\
3524\left(v_{\mathrm{O}-\mathrm{H}}\right) \\
1611\left(\delta_{\mathrm{H}-\mathrm{O}-\mathrm{H}}\right)\end{array}$ & $\begin{array}{l}3670\left(v_{\mathrm{O}-\mathrm{H}}\right)^{\mathrm{f}}, \\
3580\left(v_{\mathrm{O}-\mathrm{H}}\right)^{\mathrm{f}}, \\
1634\left(\delta_{\mathrm{H}-\mathrm{O}-\mathrm{H}}\right)^{\mathrm{f}}\end{array}$ & [37] \\
\hline
\end{tabular}

${ }^{\mathrm{a}} \mathrm{M} 06-\mathrm{L} / 6-31++\mathrm{G}(\mathrm{d}, \mathrm{p})$ level of theory; scale factor for vibrations above $1000 \mathrm{~cm}^{-1}$ is 0.949 while vibrations below are unscaled; bold text denotes values that can be compared directly. ${ }^{b}$ From left to right, frequencies at low, medium and high gas-phase equilibrium pressure, respectively. ${ }^{\mathrm{c}}$ Frequencies for para- and ortho-hydrogen, respectively. ${ }^{\mathrm{d}}$ Values for carbonate-like species. ${ }^{\mathrm{e}}$ Fermi resonancesbetween Raman-active and combination mode vibrations. ${ }^{\mathrm{f}}$ Vibrations for adsorbed water molecules originated from reaction of ethene:oxygen mixtures in (Na, K)-ETS10 .

\section{Conclusions}

The interactions of $\mathrm{H}_{2}, \mathrm{~N}_{2}, \mathrm{CO}_{2}, \mathrm{CH}_{4}$ and $\mathrm{H}_{2}$ Ospecies with ETS-10 having extra framework sodium cations were studied by means of density functional theory. It was found that the M06-L exchange-correlation functional together with double zeta basis sets, with or without diffuse functions, provides enthalpies for the interaction of these atmospheric gases with NaETS-10 in very good agreement with available experimental isosteric heats of adsorption if basis 
set superposition errors are introduced in the structural optimization and energy calculation. It was found that the adsorbates interact preferentially with the sodium cation located in the large 12 MR ring of ETS-10. Upon interaction with such cations, adsorbates become slightly positively charged and the sodium ion gains some negative charge. The strength of the gasmaterial interaction increases in the order $\mathrm{H}_{2}<\mathrm{CH}_{4}<\mathrm{N}_{2}<\mathrm{CO}_{2}<\mathrm{H}_{2} \mathrm{O}$, with enthalpies of interaction at $T=298.15 \mathrm{~K}$ ranging between $-12.2 \mathrm{~kJ} / \mathrm{mol}\left(\mathrm{H}_{2}\right)$ and $-60.6 \mathrm{~kJ} / \mathrm{mol}\left(\mathrm{H}_{2} \mathrm{O}\right)$. The vibrational frequencies calculated at the M06-L/6-31++G(d,p) level of theory are in very good agreement with the experimental vibrations characteristic of the formation of $\mathrm{Na}^{+} \cdots$ adsorbate adducts for $\mathrm{Na}$ cations located in the 12-membered channels. The calculations suggest that due to the strong gas-material interactions found for the polar $\mathrm{H}_{2} \mathrm{O}$ and the quadrupolar $\mathrm{CO}_{2}$ species, the regeneration of ETS-10 materials after usage in separation and/or catalysis processes could be an energy intensive process. Note that the models studied in this work are representative of systems at very low pressure and that most of the applications for these materials are thought for large pressure. However, the adsorption behavior at such conditions is highly determined by the strength of the sorbate-sorbent and sorbate-sorbate interactions at the atomic level, and data obtained in this work is certainly relevant to understand experimental data obtained under more realistic conditions and to calibrate other computational strategies (e.g. Monte Carlo simulations). 


\section{Acknowledgments}

This work is supported by projects PTDC/EQU-EQU/100476/2008, PEst-C/EQB/LA0020/2013, and PEst-C/CTM/LA0011/2013, financed by FEDER through COMPETE - Programa Operacional Factores de Competitividade and by FCT - Fundação para a Ciência e a Tecnologia. RSP gratefully acknowledges a post-doctoral fellowship from FCT with reference SFRH/BPD/70283/2010.

\section{References}

[1] S.M. Kuznicki, US Patent 4853202 (1989).

[2] M.W. Anderson, O. Terasaki, T. Ohsuna, A. Philippou, S.P. Mackay, A. Ferreira, J. Rocha, S. Lidin, Nature, 367 (1994) 347-351.

[3] M.W. Anderson, O. Terasaki, T. Ohsuna, P.J.O. Malley, A. Philippou, S.P. Mackay, A. Ferreira, J. Rocha, S. Lidin, Philos. Mag. B, 71 (1995) 813-841.

[4] T.K. Das, A.J. Chandwadkar, S. Sivasanker, J. Mol. Catal. A Chem, 107 (1996) 199-205.

[5] X.L. Yang, P.W. Blesser, Zeolites, 17 (1996) 237-243.

[6] T.K. Das, A.J. Chandwadkar, S. Sivasanker, Aromatization of n-hexane over platinum alkaline ETS-10, in: T.S.R. Rao, G.M. Dhar (Eds.) Recent Advances in Basic and Applied Aspects of Industrial Catalysis (1998), pp. 455-462.

[7] A. Philippou, J. Rocha, M.W. Anderson, Catal. Lett., 57 (1999) 151-153.

[8] S.B. Waghmode, S.M. Sabne, S. Sivasanker, Green. Chem., 3 (2001) 285-288.

[9] E.J. Doskocil, J. Phys. Chem. B, 109 (2005) 2315-2320.

[10] R.F. Howe, Y.K. Krisnandi, Chem. Commun., (2001) 1588-1589.

[11] Y.K. Krisnandi, P.D. Southon, A.A. Adesina, R.F. Howe, Int. J. Photoenergy, 5 (2003) 131140.

[12] C.C. Pavel, K. Popa, N. Bilba, A. Cecal, D. Cozma, A. Pui, J. Radioanal. Nucl. Ch., 258 (2003) 243-248.

[13] C.B. Lopes, M. Otero, J. Coimbra, E. Pereira, J. Rocha, Z. Lin, A. Duarte, Micropor. Mesopor. Mat., 103 (2007) 325-332. 
[14] L. Lv, K. Wang, X.S. Zhao, J. Colloid Interf. Sci., 305 (2007) 218-225.

[15] A. Nalaparaju, Z.Q. Hu, X.S. Zhao, J.W. Jiang, J. Membrane Sci., 335 (2009) 89-95.

[16] D.T. Hayhurst, M. Mansour, S.M. Kuznicki, Abstr. Pap. Am. Chem. S., 202 (1991) 79-81.

[17] N.A. Al-Baghli, K.F. Loughlin, J. Chem. Eng. Data, 50 (2005) 843-848.

[18] A. Anson, S.M. Kuznicki, T. Kuznicki, T. Haastrup, Y. Wang, C.C.H. Lin, J.A. Sawada, E.M. Eyring, D. Hunter, Micropor. Mesopor. Mat., 109 (2008) 577-580.

[19] A. Nalaparaju, X.S. Zhao, J.W. Jiang, J. Phys. Chem. C, 112 (2008) 12861-12868.

[20] A. Anson, C.C.H. Lin, S.M. Kuznicki, J.A. Sawada, Chemical Engineering Science, 64 (2009) 3683-3687.

[21] S.W. Park, Y.H. Yun, S.D. Kim, S.T. Yang, W.S. Ahn, G. Seo, W.J. Kim, J. Porous Mat., 17 (2010) 589-595.

[22] M. Shi, Applications of titanosilicate molecular sieve in gas separation Department of Chemical and Materials Engineering, University of Alberta - Edmonton, Alberta 2013, pp. 1182.

[23] A. Anson, C.C.H. Lin, T.M. Kuznicki, S.M. Kuznicki, Chemical Engineering Science, 65 (2010) 807-811.

[24] A. Anson, Y. Wang, C.C.H. Lin, T.M. Kuznicki, S.M. Kuznicki, Chemical Engineering Science, 63 (2008) 4171-4175.

[25] S.M. Kuznicki, A. Anson, A. Koenig, T.M. Kuznicki, T. Haastrup, E.M. Eyring, D. Hunter, J. Phys. Chem. C, 111 (2007) 1560-1562.

[26] A.J.M. deMan, J. Sauer, J. Phys. Chem., 100 (1996) 5025-5034.

[27] W.Y. Ching, Y.N. Xu, Z.Q. Gu, Phys. Rev. B, 54 (1996) 15585-15589.

[28] S. Bordiga, G.T. Palomino, A. Zecchina, G. Ranghino, E. Giamello, C. Lamberti, J. Chem. Phys., 112 (2000) 3859-3867.

[29] A.M. Zimmerman, D.J. Doren, R.F. Lobo, J. Phys. Chem. B, 110 (2006) 8959-8964.

[30] S.B. Waghmode, R. Vetrivel, C.S. Gopinath, S. Sivasanker, J. Phys. Chem. B, 108 (2004) 11541-11548.

[31] A.M. Shough, D.J. Doren, B. Ogunnaike, Chem. Mater., 21 (2009) 1232-1241.

[32] M.L. Guo, Z.C. Feng, G.N. Li, J.P. Hofmann, E.A. Pidko, P. Magusin, Q. Guo, B.M. Weckhuysen, E.J.M. Hensen, F.T. Fan, C. Li, Chemistry A European Journal, 18 (2012) 1207812084.

[33] A. Zecchina, C.O. Arean, G.T. Palomino, F. Geobaldo, C. Lamberti, G. Spoto, S. Bordiga, Phys. Chem. Chem. Phys., 1 (1999) 1649-1657.

[34] M. Kishima, T. Okubo, J. Phys. Chem. B, 107 (2003) 8462-8468.

[35] S. Bordiga, C. Paze, G. Berlier, D. Scarano, G. Spoto, A. Zecchina, C. Lamberti, Catal. Today, 70 (2001) 91-105. 
[36] C.O. Arean, G.T. Palomino, A. Zecchina, S. Bordiga, F.X. Llabrés i Xamena, C. Paze, Catal. Lett., 66 (2000) 231-235.

[37] Y.K. Krisnandi, R.F. Howe, Appl. Catal. A Gen, 307 (2006) 62-69.

[38] F.X. Llabrés i Xamena, A. Zecchina, Phys. Chem. Chem. Phys., 4 (2002) 1978-1982.

[39] M.L. Pinto, J. Rocha, J.R.B. Gomes, J. Pires, J. Am. Chem. Soc., 133 (2011) 6396-6402.

[40] X.Q. Wang, A.J. Jacobson, Chem. Commun., (1999) 973-974.

[41] J.R.B. Gomes, M.N.D.S. Cordeiro, M. Jorge, Geochim. Cosmochim. Ac., 72 (2008) 44214439.

[42] M.J. Frisch, G.W. Trucks, H.B. Schlegel, G.E. Scuseria, M.A. Robb, J.R. Cheeseman, G. Scalmani, V. Barone, B. Mennucci, G.A. Petersson, H. Nakatsuji, M. Caricato, X. Li, H.P. Hratchian, A.F. Izmaylov, J. Bloino, G. Zheng, J.L. Sonnenberg, M. Hada, M. Ehara, K. Toyota, R. Fukuda, J. Hasegawa, M. Ishida, T. Nakajima, Y. Honda, O. Kitao, H. Nakai, T. Vreven, J. Montgomery, J. A., J.E. Peralta, F. Ogliaro, M. Bearpark, J.J. Heyd, E. Brothers, K.N. Kudin, V.N. Staroverov, R. Kobayashi, J. Normand, K. Raghavachari, A. Rendell, J.C. Burant, S.S. Iyengar, J. Tomasi, M. Cossi, N. Rega, J.M. Millam, M. Klene, J.E. Knox, J.B. Cross, V. Bakken, C. Adamo, J. Jaramillo, R. Gomperts, R.E. Stratmann, O. Yazyev, A.J. Austin, R. Cammi, C. Pomelli, J.W. Ochterski, R.L. Martin, K. Morokuma, V.G. Zakrzewski, G.A. Voth, P. Salvador, J.J. Dannenberg, S. Dapprich, A.D. Daniels, Ö. Farkas, J.B. Foresman, J.V. Ortiz, J. Cioslowski, D.J. Fox, Gaussian 09, Rev. B.01, Gaussian, Inc., Wallingford CT, (2009).

[43] S. Simon, M. Duran, J.J. Dannenberg, J. Chem. Phys., 105 (1996) 11024-11031.

[44] A.D. Becke, J. Chem. Phys., 98 (1993) 5648-5652.

[45] C.T. Lee, W.T. Yang, R.G. Parr, Phys. Rev. B, 37 (1988) 785-789.

[46] J.P. Perdew, J.A. Chevary, S.H. Vosko, K.A. Jackson, M.R. Pederson, D.J. Singh, C. Fiolhais, Phys. Rev. B, 46 (1992) 6671-6687.

[47] J.P. Perdew, K. Burke, M. Ernzerhof, Phys. Rev. Lett., 77 (1996) 3865-3868.

[48] J.P. Perdew, K. Burke, M. Ernzerhof, Phys. Rev. Lett., 78 (1997) 1396-1396.

[49] A.D. Becke, Phys. Rev. A., 38 (1988) 3098-3100.

[50] J.P. Perdew, Phys. Rev. B, 33 (1986) 8822-8824.

[51] S. Grimme, J. Comp. Chem., 27 (2006) 1787-1799.

[52] Y. Zhao, D.G. Truhlar, J. Chem. Phys., 125 (2006) 194101:1-18.

[53] Y. Zhao, D.G. Truhlar, Theor. Chem. Acc., 120 (2008) 215-241.

[54] P.C. Harihara, J.A. Pople, Theor. Chim. Acta., 28 (1973) 213-222.

[55] M.M. Francl, W.J. Pietro, W.J. Hehre, J.S. Binkley, M.S. Gordon, D.J. Defrees, J.A. Pople, J. Chem. Phys., 77 (1982) 3654-3665.

[56] T. Clark, J. Chandrasekhar, G.W. Spitznagel, P.V.R. Schleyer, J. Comp. Chem., 4 (1983) 294-301. 
[57] M.L. Guo, E.A. Pidko, F.T. Fan, Z.C. Feng, J.P. Hofmann, B.M. Weckhuysen, E.J.M. Hensen, C. Li, J. Phys. Chem. C, 116 (2012) 17124-17133.

[58] O. Talu, S.M. Kuznicki, Fundamentals on Adsorption Conference, FOA6, Giens, France, May 24-28, 1998.

[59] J.P.P. Ramalho, J.R.B. Gomes, F. Illas, Rsc. Adv., 3 (2013) 13085-13100.

[60] M. Fischer, J.R.B. Gomes, M. Jorge, Molecular Simulation, (2013), in press, http://dx.doi.org/10.1080/08927022.2013.829228.

[61] P.B. Whittaker, X. Wang, K. Regenauer-Lieb, H.T. Chua, Phys. Chem. Chem. Phys., 15 (2013) 473-482.

[62] G.R. Birkett, D.D. Do, Langmuir, 22 (2006) 9976-9981.

[63] S.J. Luo, Y. Zhao, D.G. Truhlar, J. Phys. Chem. Lett., 3 (2012) 2975-2979.

[64] L. Ferrighi, G.K.H. Madsen, B. Hammer, J. Chem. Phys., 135 (2011)084704:1-8.

[65] J. Toda, M. Fischer, M. Jorge, J.R.B. Gomes, Chem. Phys. Lett., 587 (2013) 7-13.

[66] M. Gallo, T.M. Nenoff, M.C. Mitchell, Fluid Phase Equilibria, 247 (2006) 135-142.

[67] J.R.B. Gomes, M.A.V.R. Da Silva, Int. J. Quantum Chem., 101 (2005) 860-868.

[68] X. Yang, J.L. Paillaud, H.F.W.J. van Breukelen, H. Kessler, E. Duprey, Micropor Mesopor Mat, 46 (2001) 1-11.

[69] J.P. Merrick, D. Moran, L. Radom, J. Phys. Chem.. A, 111 (2007) 11683-11700.

[70] I.M. Alecu, J.J. Zheng, Y. Zhao, D.G. Truhlar, J.. Chem. Theory. Comput., 6 (2010) 28722887.

[71] K. Nakamoto, Infrared and Raman Spectra of Inorganic and Coordination Compounds, Handbook of Vibrational Spectroscopy, John Wiley \& Sons, Ltd, 2006.

[72] G. Herzberg, Astrophys. J. 87 (1938) 428-437. 